\title{
Interactions between the midbrain superior colliculus and the basal ganglia
}

\section{Peter Redgrave ${ }^{1 *}$, Veronique Coizet ${ }^{1,2}$, Eliane Comoli ${ }^{1,3}$, John G. McHaffie ${ }^{4}$, Mariana Leriche ${ }^{1}$, Nicolas Vautrelle $^{1}$, Lauren M. Hayes ${ }^{1}$ and Paul Overton ${ }^{1}$}

Neuroscience Research Unit, Department of Psychology, University of Sheffield, Sheffield, UK

2 INSERM U836 - GIN - Unit 1, Joseph Fourier University, Grenoble, France

${ }^{3}$ Department of Physiology, School of Medicine of Ribeirão Preto, University of São Paulo, São Paulo, Brazil

${ }^{4}$ Department of Neurobiology and Anatomy, Wake Forest University School of Medicine, Winston Salem, NC, USA

\section{Edited by:}

Jose L. Lanciego, University of

Navarra, Spain

Reviewed by:

Alino Martinez-Marcos, Universidad de

Castilla, Spain

Guillermina Lopez-Bendito, University

Miguel Hernandez, Spain

José A. Armengol, University Pablo de

Olavide, Spain

\section{${ }^{*}$ Correspondence:}

Peter Redgrave, Neuroscience

Research Unit, Department of

Psychology, University of Sheffield,

Sheffield S10 2TP, UK.

e-mail: p.redgrave@sheffield.ac.uk

An important component of the architecture of cortico-basal ganglia connections is the parallel, re-entrant looped projections that originate and return to specific regions of the cerebral cortex. However, such loops are unlikely to have been the first evolutionary example of a closed-loop architecture involving the basal ganglia. A phylogenetically older, series of subcortical loops can be shown to link the basal ganglia with many brainstem sensorimotor structures. While the characteristics of individual components of potential subcortical re-entrant loops have been documented, the full extent to which they represent functionally segregated parallel projecting channels remains to be determined. However, for one midbrain structure, the superior colliculus (SC), anatomical evidence for closed-loop connectivity with the basal ganglia is robust, and can serve as an example against which the loop hypothesis can be evaluated for other subcortical structures. Examination of ascending projections from the SC to the thalamus suggests there may be multiple functionally segregated systems. The SC also provides afferent signals to the other principal input nuclei of the basal ganglia, the dopaminergic neurones in substantia nigra and to the subthalamic nucleus. Recent electrophysiological investigations show that the afferent signals originating in the SC carry important information concerning the onset of biologically significant events to each of the basal ganglia input nuclei. Such signals are widely regarded as crucial for the proposed functions of selection and reinforcement learning with which the basal ganglia have so often been associated.

Keywords: superior colliculus, thalamus, subthalamus, striatum, substantia nigra, dopamine, selection, reinforcement learning

The basal ganglia are one of the fundamental processing units of the vertebrate brain. As such they have evolved multiple connections with most regions of the cerebral cortex, limbic system, thalamus, and numerous structures in the hindbrain. An important, although not exclusive, component of the basal ganglia connectional architecture are the parallel looped projections that originate in and return to external structures. The most prominent examples of this configuration are the looped projections connecting the basal ganglia with the cerebral cortex (Alexander et al., 1986). However, prior to the evolutionary expansion of the cerebral cortex, it was probably the co-evolution of the basal ganglia with subcortical sensorimotor structures that established basic looped circuitry onto which the cortex was later grafted (Reiner, 2010). The purpose of the present article is to detail the functional anatomy of connections between one of the evolutionary primitive sensorimotor structures of the brainstem, the superior colliculus (SC), and the basal ganglia. The SC was chosen as a template structure because its anatomy (Grantyn and Moschovakis, 2004; May, 2006), electrophysiology (Boehnke and Munoz, 2008), and especially its role in the re-direction of gaze (Sparks, 1986; Dean et al., 1989; Stein and Meredith, 1993; Grantyn and Moschovakis, 2004), are comparatively well understood. The connections between the SC and basal ganglia are also well characterized (Hikosaka et al., 2000; McHaffie et al., 2005). Our appreciation of the structure and function of the SC can therefore help provide insights, first, into how the basal ganglia might contribute to shifting the direction of gaze (which may serve as a general model), and second, how the SC might contribute to general functions performed by the basal ganglia.

\section{TECTO-BASAL GANGLIA CONNECTIONAL ARCHITECTURE PARALLEL LOOPS}

Alexander et al. (1986) were the first to appreciate the parallel-loop configuration of the connections between the cerebral cortex and the basal ganglia. These parallel, partially segregated loops, pass sequentially through the basal ganglia nuclei and return to cortical regions of origin via a relay in the thalamus (Joel and Weiner, 1994; Groenewegen et al., 1999; Haber, 2003). Although the loops originate from functionally diverse regions of cerebral cortex, the internal micro-circuits of the basal ganglia with which they make contact are qualitatively similar in terms of cell-type, neurochemistry, and intrinsic connectivity (Voorn et al., 2004). Much experimental evidence now supports the concept that cortico-basal gangliathalamo-cortical channels have an important anatomical and functional significance (Alexander et al., 1986; Parent and Hazrati, 1995; Middleton and Strick, 2000). Consequently, they have been incorporated into many contemporary conceptual and computational 
models of the basal ganglia (Mink, 1996; Redgrave et al., 1999a; Gurney et al., 2001a,d; Frank and Claus, 2006; Humphries et al., 2006; Frank et al., 2007). However, it is likely that the cortico-basal ganglia loops were pre-dated by looped projections connecting subcortical structures with the basal ganglia (Figure 1).

This idea was originally proposed with specific reference to the SC by May and Hall (1984) and later expanded upon by McHaffie et al. (2005). Thus, in addition to descending projections to the pons and the medulla (Redgrave et al., 1987), both the superficial and deep layers of the SC have ascending connections with targets in the thalamus, including the lateral posterior nucleus (Lin et al., 1984; Abramson and Chalupa, 1988; Berson and Graybiel, 1991; Harting et al., 2001b) and the midline/intralaminar nuclear complex (Chevalier and Deniau, 1984; Krout et al., 2001). Significantly, the ascending projections of the SC specifically target regions of the thalamus that provide major afferents to the striatum and STN (Takada et al., 1985; Feger et al., 1994; Van der Werf et al., 2002) (Figure 2). This arrangement suggests the SC is an important afferent source of sensory and motor information, as well as being a principal recipient of basal ganglia output $(\mathrm{McHaffie}$ et al., 2005).

A detailed examination of tecto-thalamic projections suggests there are at least two functionally segregated systems, one originating from the superficial layers and the other from the deep layers. Output from the exclusively visual superficial layers is directed to the extrageniculate visual thalamus (lateral posterior/pulvinar complex) (Lin et al., 1984; Abramson and Chalupa, 1988; Berson and Graybiel, 1991; Harting et al., 2001b). In addition to its efferent connections with extrastriate visual cortex (Updyke, 1981; Raczkowski and Rosenquist, 1983), this lateral posterior region of the thalamus also projects extensively to localized regions of the striatum, including lateral aspects of the body and tail of the caudate and dorsal putamen (Lin et al., 1984; Takada et al., 1985; Harting et al., 2001a,b; Cheatwood et al., 2003). This tecto-thalamic projection therefore provides a fairly direct route by which early visual input can be made available to the striatum (Lin et al., 1984; Takada et al., 1985; Harting et al., 2001a,b). The next link of this loop is the "direct" striatonigral projection which relays information from the visual thalamus to the ventrolateral aspects of substantia nigra, pars reticulata (Deniau et al., 1996; Gerfen and Wilson, 1996; Deniau et al., 2007). It is within these nigral regions that signals related to visual orienting are most frequently encountered (Hikosaka and Wurtz, 1983) and from which the final nigrotectal link of the visual loop returns to the SC (May and Hall, 1984; Harting et al., 1988; Redgrave et al., 1992a).

The ascending projections from the SC deep layers are to the thalamic intralaminar nuclei; the caudal intralaminar complex (centromedian and parafasicular nuclei) and the rostral intralaminar thalamic group (central lateral, paracentral, and central medial nuclei) (Chevalier and Deniau, 1984; Krout et al., 2001). Since both the caudal and rostral intralaminar thalamic nuclei provide topographically ordered projections to all functional territories within the striatum (Mengual et al., 1999; Van der Werf et al., 2002; Smith et al., 2004), the colliculo-thalamo-basal ganglia-collicular projections involving these sub-regions of the intralaminar thalamus may themselves represent sub-components of functionally independent parallel loops. The "direct" and "indirect" components of the tecto-thalamo-basal ganglia-tectal loops that project between the intrinsic nuclei of the basal ganglia are well known and have been reviewed extensively elsewhere (Tulloch et al., 1978; Deniau et al., 1996; Gerfen and Wilson, 1996; Smith et al., 1998). Similarly, the projections from both basal ganglia output nuclei (substantia nigra pars reticulata and the internal globus pallidus) back to the SC have also been described in detail (Graybiel, 1978; Harting et al., 1988; Deniau and Chevalier, 1992; Redgrave et al., 1992a,b; Takada et al., 1994).

Together these observations provide strong evidence for a primitive pattern of looped connections which originate in different parts of the SC, project in parallel via the thalamus through the basal ganglia and return to the same regions in the SC. Before leaving this
A

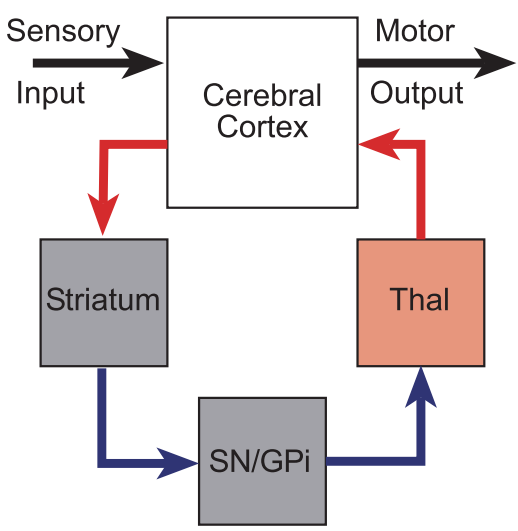

B
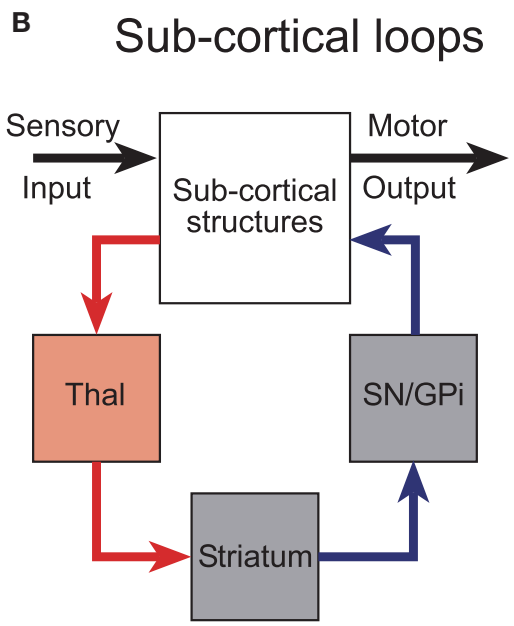

FIGURE 1 | Cortical and subcortical sensorimotor loops through the basal ganglia (modified with permission from McHaffie et al., 2005). (A)The position of the thalamic relay is on the return arm of cortical loops, while for subcortical loops, the thalamic relay is on the input side. (B) Predominantly excitatory regions and connections are in red; inhibitory regions and connections are in blue. GPi, internal globus pallidus; SN, substantia nigra; Thal, thalamus. 


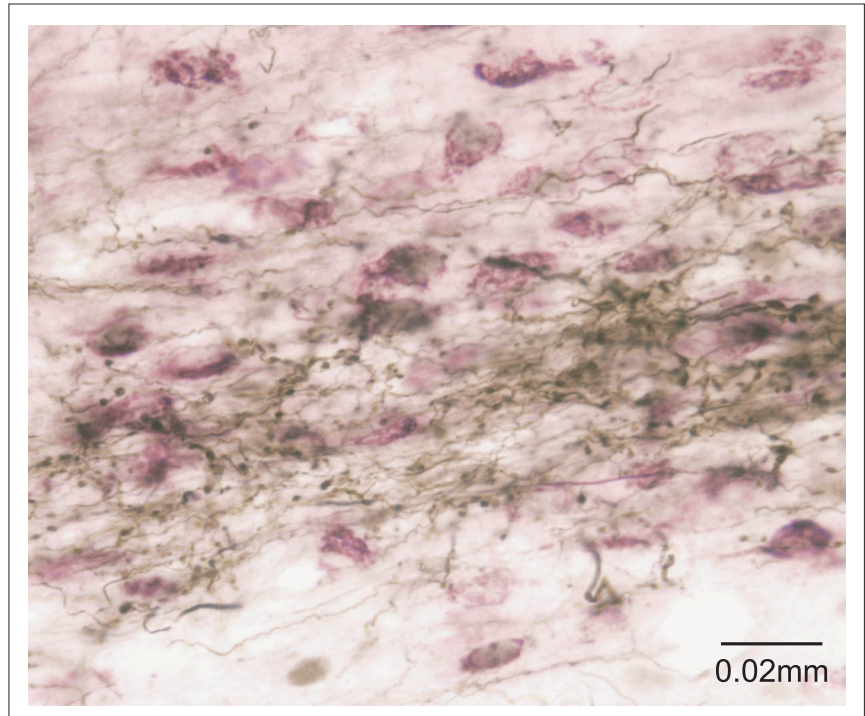

FIGURE 2 |The tecto-thalamo-striatal projection. Thalamo-striatal neurones in the central medial nucleus of the thalamus labeled with CTb (purple) retrogradely transported from the striatum, surrounded by terminal boutons labeled with biotinylated dextran (brown) anterogradely transported from the deep layers of the superior colliculus.

topic, it is worth noting that to view the sub-cortical basal ganglia loops as segregated closed channels of communication is undoubtedly simplistic (cf. Joel and Weiner, 1994; Haber, 2003) for similar comments about the cortico-basal ganglia loops). The synaptic relays between the different parts of each loop (in the structures of origin, the thalamus, and the various basal ganglia nuclei), represent nodal points whereby signals originating from outside the loop can modulate activity circulating within the loop.

\section{A SUB-CORTICAL "HYPER-DIRECT" PROJECTION}

In recent years, evidence has accumulated that the STN should be considered as an important entry point to the basal ganglia (Nambu et al., 2002), in addition to being an intrinsic relay in the classical "indirect-projection" (Albin et al., 1989). Thus, cortical afferents arising mainly from prefrontal and motor areas make direct contact with the STN (Afsharpour, 1985; Nambu et al., 2002). However, since the basal ganglia, including the STN, were present prior to the evolutionary expansion of cerebral cortex (Reiner, 2010), we might expect the STN also to receive inputs from ancient brainstem structures.

Evidence consistent with this suggestion for the SC was initially provided by Tokuno et al. (1994) and further emphasized by Coizet et al. (2009). In the latter study, tracer injections into the lateral deep SC layers produced dense anterogradely labeled terminals in the STN (Figure 3). Ultrastructural examination of the tectosubthalamic projection revealed a high proportion of asymmetrical synaptic contacts suggesting that the projection is predominantly excitatory. In contrast, the STN was virtually devoid of terminal labeling when injections were directed to the medial SC. Injections of retrograde tracers into the STN confirmed small- to mediumsized multi-polar neurones concentrated in the lateral deep layers of the SC were the source of the tecto-subthalamic projection.
Together these results suggest that phylogenetically older structures such as the SC established direct access to the basal ganglia output nuclei via a subcortical "hyperdirect" projection.

\section{A DIRECT TECTO-NIGRAL PROJECTION}

A further important input to the basal ganglia occurs via afferents to DA cell groups in the ventral midbrain (substantia nigra pars compacta, SNc and the ventral tegmental area, VTA) (Lindvall and Bjorklund, 1974). Inputs to DA containing regions of the ventral midbrain from several brainstem structures, including the pedunculopontine tegmental nucleus (Mena-Segovia et al., 2004; Winn, 2006), the lateral dorsal tegmental nucleus (Omelchenko and Sesack, 2005), the dorsal raphe (Benarroch, 2009), the rostromedial tegmental nucleus (Jhou et al., 2009), the periacqueductal gray (Omelchenko and Sesack, 2010) and the parabrachial nucleus (Coizet et al., 2010), have been described. However, given the sensitivity of DA neurones to unexpected biologically salient events (Schultz, 1998; Redgrave et al., 1999b; Horvitz, 2000; Redgrave and Gurney, 2006; Redgrave et al., 2008) it is the direct connections with sensory structures such as the SC that has attracted much recent interest.

A direct tectonigral pathway (Figure 3) was first described in rodents by Comoli et al. (2003) and later confirmed in cat (McHaffie et al., 2006), and monkey (May et al., 2009). Using anterograde and retrograde tracing techniques supported by ultrastructural analysis in the rat, Comoli et al. (2003) showed that the tectonigral pathway comprises several functionally distinguishable components. Anterogradely labeled tectonigral boutons formed both asymmetric (presumed excitatory) and symmetric (presumed inhibitory) synapses with both tyrosine hydroxylase-positive and -negative elements in substantia nigra pars compacta. The projection is also broadly topographical with neurones in lateral SC projecting strongly to lateral SNc while more medial regions of SNc and VTA receive predominantly from the medial intermediate layers (Comoli et al., 2003) and periaqueductal gray (Omelchenko and Sesack, 2010).

A particularly important feature of SC projections to SNc is that many tectonigral cells-of-origin also appear to send an ascending axon collateral to the thalamus (Figure 4). In a double retrograde tracing study (Coizet et al., 2007), significant double-labeling was reported after injections involving tectonigral fibers and ascending tectothalamic projections. Separate injections into the rostralintralaminar, caudal-intralaminar, and ventromental thalamic nuclei each double-labeled between 15 and 30\% of tectonigral neurones in the lateral deep SC. However, whether the double labeling associated with different targets in the thalamus are part of the same or separate projection systems is unresolved. If they are separate, the proportions of double labeled cells added together could potentially give a total of $\sim 70 \%$.

This brief anatomical overview confirms that the SC, one of the primitive sensorimotor structures in the brainstem, is not only an important recipient of basal ganglia processed information but is also a critical source of input. Direct afferent connections target both the STN and DA cell groups in the ventral midbrain while indirect input to the striatum occurs via relays in the thalamus. The functional implications of such this sub-cortical architecture will now be considered, first, in terms of how the basal ganglia 


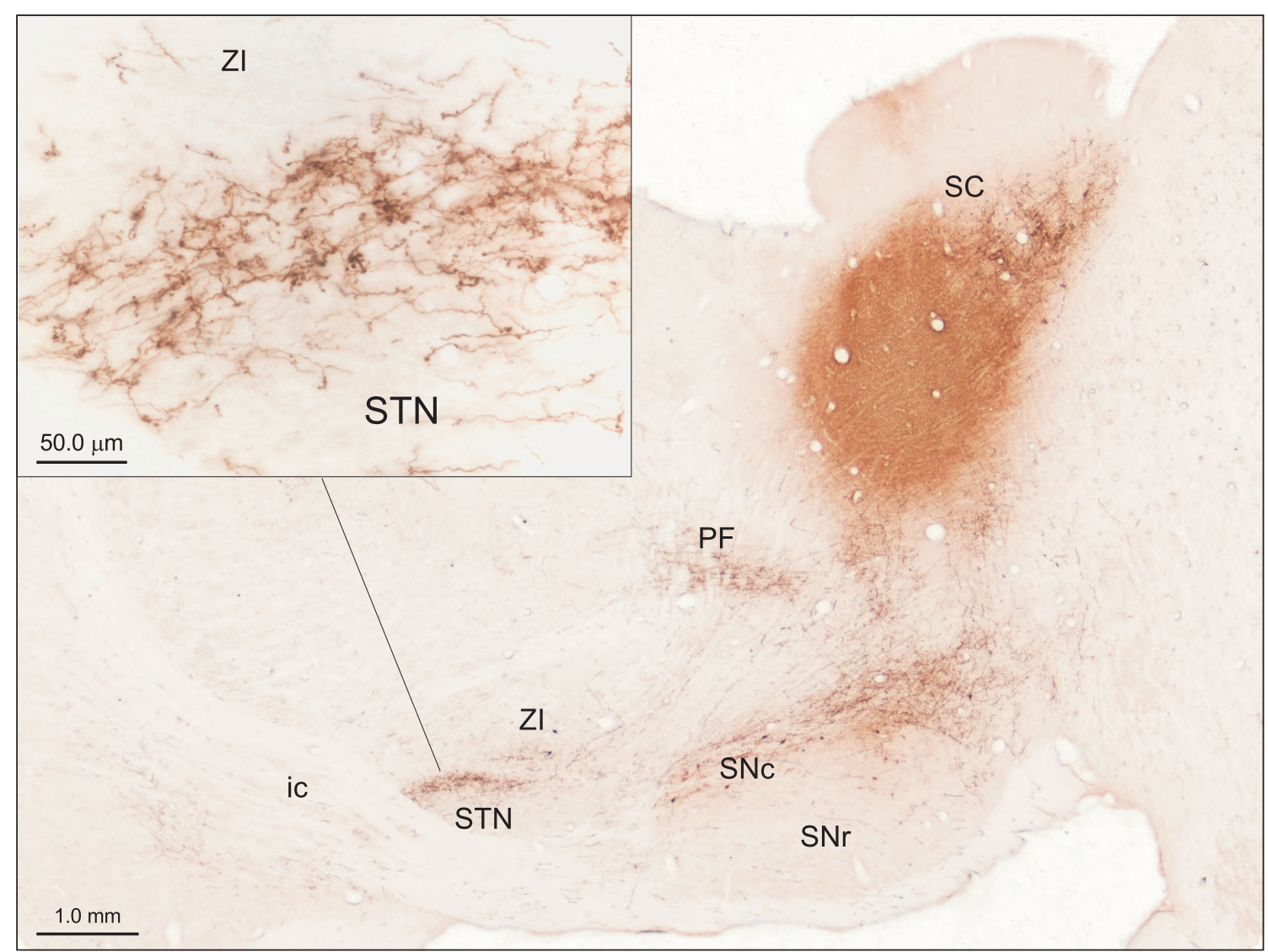

FIGURE 3 |The tecto-subthalamic and tecto-nigral projections in rat (modified with permission from Coizet et al., 2009). A large injection of the anterograde tracer PHA-L into the deep layers of the lateral superior colliculus (SC) produced dense fiber and terminal labeling in substantia nigra pars compacta (SNc) and subthalamic nucleus (STN). Note the dense clusters of terminal boutons, presumably surrounding neuronal cell bodies in STN (see inset). The tecto-thalamic projection was also confirmed in this case with terminal labeling evident in the parafasicular thalamic nucleus (PF). ic, Internal capsule; SNr, substantia nigra pars reticulate; ZI, zona incerta.

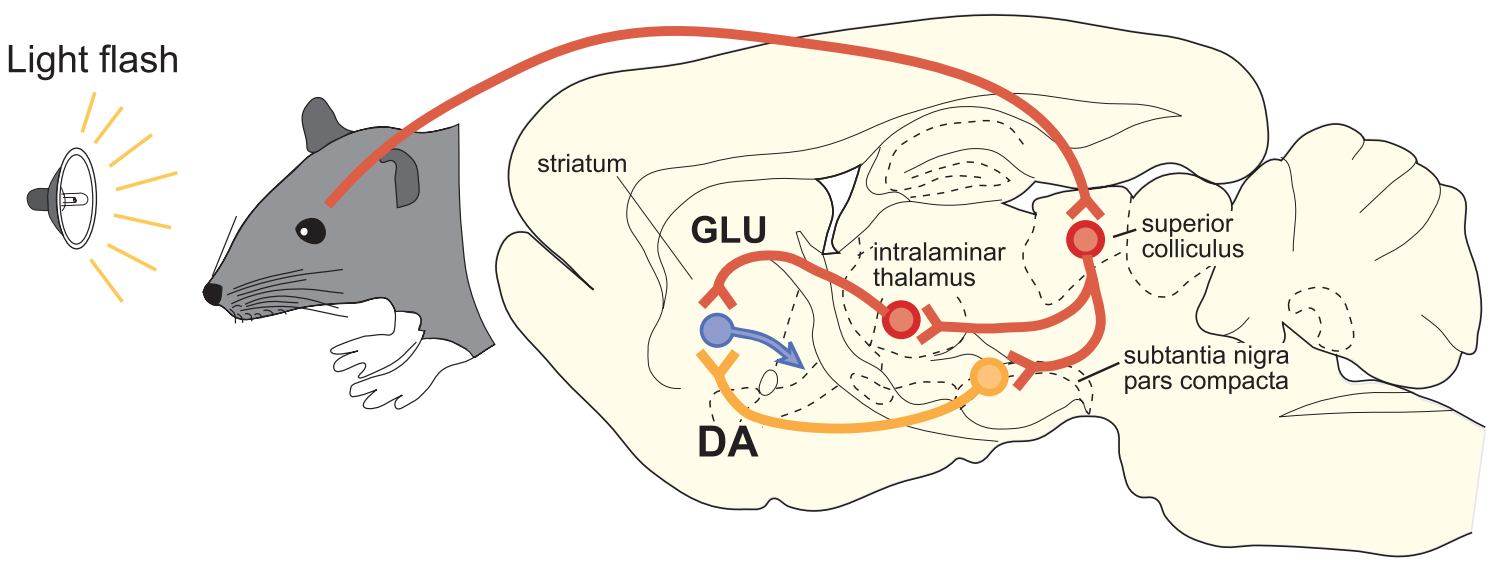

FIGURE 4 |A schematic illustration of the proposed convergence of short-latency phasic inputs to the striatum elicited by an unpredicted visual event. Direct retinal input to the superior colliculus could be re-directed, via branched projections to the intralaminar thalamic nuclei and to the substantia nigra pars compacta. At present, the identities of the neurotransmitters used in branched connections from the superior colliclus are unknown. Consequent, potentially converging phasic inputs to the striatum from intralaminar nuclei (GLU, glutamate) and substantia nigra (DA, dopamine) are likely to play a critical role in reinforcement learning. 
modulates SC-mediated gaze shifts, and second, how aspects of basal ganglia function might benefit from short-latency sensory input from the SC.

\section{FUNCTIONAL IMPLICATIONS}

Despite suggestions implicating the basal ganglia in a wide range of functions, accumulating evidence points to a generic role in selection (Mink, 1996; Redgrave et al., 1999a; Hikosaka et al., 2000) and reinforcement learning (Schultz, 1998; Wise, 2004; Berridge, 2007). Selection would be an emergent property of the parallel loopedarchitecture that connects the basal ganglia with most external structures (Alexander et al., 1986; McHaffie et al., 2005). Output signals from the basal ganglia are tonically active and inhibitory (Chevalier and Deniau, 1990). Selective suppression of inhibitory output in some loops while maintaining or increasing it in others (selective disinhibition Chevalier and Deniau, 1990) would select the targets of disinhibited loops (Redgrave et al., 1999a). Selection as a property of basal ganglia macro-architecture has been confirmed computationally in biologically constrained simulations (Gurney et al., 2001b,c; Humphries et al., 2006) and the control of robot action selection (Prescott et al., 2006). In addition, the basal ganglia have also been associated with reinforcement learning, in particular, instrumental conditioning (Schultz, 1998; Wise, 2004; Berridge, 2007). Insofar as reinforcement acts to bias future selections, by increasing or decreasing the probability that reinforced selections will be re-selected (Thorndike, 1911), reinforcement learning is likely to be closely associated with the mechanism(s) of selection (Wickens et al., 2007; Redgrave et al., 2008). We will now consider how connections between the SC and the basal ganglia could contribute to these two important functions.

\section{SELECTION}

Faced with competing motivations and multiple sensory inputs, early vertebrates, like their modern relatives, required a means to select the most pressing stimuli and adaptive responses while suppressing less favored options. As the primary structure responsible for re-directing gaze toward or away from unexpected novel events (Dean et al., 1989; Stein and Meredith, 1993), the SC has always been confronted by pressing problems of selection. The situation arises because the retinotectal visual system can simultaneously represent numerous events, each one of which could potentially initiate a change of gaze. A selection architecture that can evaluate which of multiple simultaneously presenting stimuli is the most urgent, is essential.

One possibility would be to solve the problem locally with mutually inhibitory connections between all elements in the SC's sensorimotor maps (Snaith and Holland, 1990). However, on what basis would this reciprocally connected inhibitory network operate? Simple rules (e.g., size/speed/contrast) would run the risk of ignoring the near threshold sensory stimuli (which often foretell the beginning of life-or-death events, e.g., a small movement in the bushes or the snap of a twig), in favor of physically salient but innocuous stimuli, or on other occasions, miss the obvious. An alternative would be to have a system fully appraised of the range current motivational, contextual, and sensory variables perform selections according to the most pressing needs of the organism (Mink, 1996; Redgrave et al., 1999a). Perhaps it is for this reason the $\mathrm{SC}$ requires a contribution from the basal ganglia to perform what seems to be a simple reflex redirection of gaze. Note that the initiation of gaze-shifts to un-predicted sensory events is typically preceded by a pause in inhibitory nigrotectal output activity (Hikosaka et al., 2000). The looped architecture connecting the SC to the basal ganglia via the dorsal thalamus is a candidate mechanism to perform the pre-attentive selections required to determine whether gaze should be shifted, and if so, to which stimulus (McHaffie et al., 2005).

\section{INTERRUPT?}

The "hyper-direct" connections from the SC to the STN could provide a mechanism whereby early visual signals can influence basal ganglia output in advance of information circulating in tecto-basal ganglia loops. Because the subthalamo-nigral projection is excitatory (Smith et al., 1998) and the nigrotectal pathway is inhibitory (Chevalier and Deniau, 1990), a burst of activity in the STN transmitted to nigrotectal neurones would deliver a pulse of inhibitory signals to the SC. Two potential, although not necessarily exclusive, functions for such signals have been proposed. First, a vital part of the process by which attention is switched and gaze redirected is to interrupt or close down currently open/selected channels. A short-latency burst of inhibitory nigrotectal activity initiated by the STN could interrupt or break current gaze-fixation (Gillies and Willshaw, 1998; Redgrave et al., 1999a). Alternatively, Mink (1996) has proposed that a widely broadcast excitatory signal from the STN to basal ganglia output nuclei could be part of a mechanism to suppress motor programs that would otherwise interfere with desired movements. However, our finding in the rat that "hyperdirect" input to the STN comes only from the lateral SC (Coizet et al., 2007) raises problems for both suggestions. First, the ecology of the rodent is such that threatening stimuli are most frequently detected in the upper visual field, which according to the retinocentric map, is represented in the medial SC (Dean et al., 1989). In the class of stimuli that required the ongoing behavior of rodents to be interrupted, overhead predators would certainly be included. Similarly, it is not immediately apparent why selection mechanisms required to distinguish between multiple visual events in the upper field might require a radically different, non-STN associated architecture. The question of why typically non-threatening events in the lower visual field of rodents have direct access to the basal ganglia via the STN, whereas defense-related circuitry of the medial colliculus appears to operate through a different architecture remains to be answered.

\section{REINFORCEMENT}

Insofar as reinforcement operates to bias future behavioral selections, the association between reinforcement learning and the basal ganglia is to be expected (Wickens, 1993; Schultz, 1998; Wise, 2004; Arbuthnott and Wickens, 2007). The mechanisms proposed for adjusting the sensitivities of the striatum to "reinforced" and "nonreinforced" inputs are long term potentiation (LTP) and long term depression (LTD) (Centonze et al., 2001; Reynolds and Wickens, 2002; Calabresi et al., 2007). Selectivity is achieved by reinforcement acting specifically on recently or concurrently active inputs (Redgrave and Gurney, 2006; Arbuthnott and Wickens, 2007). In this model, reward-related inputs from the cerebral cortex are reinforced by signals from DA neurones in the ventral midbrain 
(Schultz, 1998). The pattern of neural activity that has received most attention in this regard is the short-latency, short-duration phasic DA response (Schultz, 1998). The apparent capacity of DA neurones to signal events that are "better" or "worse" than expected (reward prediction errors) has captured the imagination of both the neuroscience (Schultz, 1998; O'Doherty et al., 2003; Ungless, 2004) and computational communities (Montague et al., 1996; Dayan and Balleine, 2002).

However, over the past decade we have argued that for DA neurones to signal estimates of reward prediction errors, the current "reward value" of an unexpected eliciting event must first be evaluated. Presumably, this would rely on sensory systems afferent to the DA neurones being able to determine the value of unpredicted stimuli. In mammals, an unexpected event typically elicits an orienting gaze-shift that brings it onto the fovea for analysis by cortical visual systems (Thorpe and Fabre-Thorpe, 2001). The latency of these gaze-shifts are normally in the range 150-200 ms (Hikosaka and Wurtz, 1983; Jay and Sparks, 1987). Since the latencies of phasic DA responses are normally shorter ( 70-100 ms) (Schultz, 1998), they must be initiated on the basis of pre-attentive, pre-gaze-shift sensory processing. In a series of investigations, we established that the SC is the most likely source of short-latency visual input that drives phasic DA responses. First, as described above, a direct tectonigral projection (Figure 3 ) has been observed in rat (Comoli et al., 2003), cat (McHaffie et al., 2006), and monkey (May et al., 2009). Second, SC visual response latencies are always shorter than those recorded in DA neurones (Jay and Sparks, 1987; Schultz, 1998; Comoli et al., 2003). Third, visual-evoked activity in substantia nigra is abolished when the visual (superficial) layers of the SC are removed (Comoli et al., 2003). Fourth, local disinhibition of the SC in anesthetized animals restores visual sensitivity to DA neurones in substantia nigra and the resultant visually evoked DA release into the striatum (Dommett et al., 2005). Consequently, we have proposed the SC as the primary, if not exclusive, source of shortlatency visual input to ventral midbrain DA neurones (Comoli et al., 2003; Dommett et al., 2005).

\section{REFERENCES}

Abramson, B. P., and Chalupa, L. M. (1988). Multiple pathways from the superior colliculus to the extrageniculate visual thalamus of the cat. J. Comp. Neurol. 271, 397-418.

Afsharpour,S. (1985). Topographical projections of the cerebral cortex to the subthalamic nucleus. J. Comp. Neurol. 236, 14-28.

Albin, R. L., Young, A. B., and Penney, J. B. (1989). The functional anatomy of basal ganglia disorders. Trends Neurosci. 12, 366-375.

Alexander, G. E., DeLong, M. R., and Strick, P. L. (1986). Parallel organization of functionally segregated circuits linking basal ganglia and cortex. Аnпи . Rev. Neurosci. 9, 357-381.

Arbuthnott, G. W., and Wickens, J. (2007). Space, time and dopamine. Trends Neurosci. 30, 62-69.

Benarroch, E. E. (2009). Serotonergic modulation of basal ganglia circuits

If the tectonigral projection is responsible for the short-latency visual activation of DA neurones, the branching collaterals to the thalamus would assume great importance for the mechanisms of reinforcement in the striatum. Presumably, short-latency sensory signals originating from the SC would be transmitted simultaneously to the striatum, via DA neurones in substantia nigra and via glutamatergic thalamostriatal neurones (Figure 4). The likely temporal convergence of widely broadcast thalamostriatal and nigrostriatal inputs evoked by the same sensory event could have important implications for experience-dependent plasticity in the basal ganglia (Centonze et al., 2001; Reynolds and Wickens, 2002; Arbuthnott and Wickens, 2007; Calabresi et al., 2007; Shen et al., 2008). Specifically, under natural conditions, striatal neurones might expect that a sensory-evoked phasic input of DA from SNc would be accompanied by a phasic input of glutamate from the thalamus. The processes most likely to be reinforced by these subcortical signals are those associated with learning the causal structure between behavioral output and biologically salient sensory events (Redgrave and Gurney, 2006; Redgrave et al., 2008). Finally, on a practical note, the possibility of having the same sensory event initiate a coincident afferent convergence of glutamatergic and DA inputs in the striatum could also have important implications for how functional MRI studies investigating basal ganglia responses to biologically salient sensory events, including reward, are interpreted (McClure et al., 2003; O'Doherty et al., 2003; Zink et al., 2004; Knutson and Cooper, 2005). The possibility that signals from the SC to the striatum via the thalamus could act in concert with phasic input from ascending DA neurones to influence striatal hemodynamic responses to salient visual events should now be considered.

\section{ACKNOWLEDGMENTS}

During the preparation of this article Peter Redgrave was supported by the Wellcome Trust, and the European Commission Framework 7 programme; Paul Overton by the BBSRC, and John G. McHaffie by the NIH (NS35008).

Dopaminergic control of synaptic plasticity in the dorsal striatum. Eur. J. Neurosci. 13, 1071-1077.

Cheatwood, J. L., Reep, R. L., and Corwin, J. (2003). The associative striatum: cortical and thalamic projections to the dorsocentral striatum in rats. Brain Res. 968, 1-14.

Chevalier, G., and Deniau, J. M. (1984). Spatio-temporal organization of a branched tecto-spinal/tectodiencephalic neuronal system. Neuroscience 12, 427-439.

Chevalier, G., and Deniau, J. M. (1990). Disinhibition as a basic process in the expression of striatal functions. Trends Neurosci. 13, 277-281.

Coizet, V., Dommett, E. J., Klop, E. M., Redgrave, P., and Overton, P. G. (2010). The parabrachial nucleus is a critical link in the transmission of short-latency nociceptive information to midbrain dopaminergic neurons. Neuroscience 168, 263-272.
Coizet, V., Graham, J. H., Moss, J., Bolam, J. P., Savasta, M., McHaffie, J. G., Redgrave, P., and Overton, P. G. (2009). Short-latency visual input to the subthalamic nucleus is provided by the midbrain superior colliculus. J. Neurosci. 29, 5701-5709.

Coizet, V., Overton, P. G., and Redgrave, P. (2007). Collateralization of the tectonigral projection with other major output pathways of superior colliculus in the rat. J. Comp. Neurol. 500, 1034-1049.

Comoli, E., Coizet, V., Boyes, J., Bolam, J. P., Canteras, N. S., Quirk, R. H., Overton, P. G., and Redgrave, P. (2003). A direct projection from superior colliculus to substantia nigra for detecting salient visual events. Nat. Neurosci. 6, 974-980.

Dayan, P., and Balleine, B. W. (2002). Reward, motivation, and reinforcement learning. Neuron 36, 285-298.

Dean, P., Redgrave, P., and Westby, G. W. M. (1989). Event or emergency? Two 
response systems in the mammalian superior colliculus. Trends Neurosci. 12, 137-147.

Deniau, J. M., and Chevalier, G. (1992). The lamellar organization of the rat substantia nigra pars reticulata distribution of projection neurons. Neuroscience 46, 361-377.

Deniau, J. M., Mailly, P., Maurice, N., and Charpier, S. (2007). "The pars reticulata of the substantia nigra: a window to basal ganglia output," in Gaba and the Basal Ganglia: From Molecules to Systems. Prog. Brain Res. Vol. 160, eds J. M. Tepper, E. D. Abercrombie, and J. P. Bolam (Amsterdam: Elsevier), 151-172.

Deniau, J. M., Menetrey, A., and Charpier, S. (1996). The lamellar organization of the rat substantia nigra pars reticulata: segregated patterns of striatal afferents and relationship to the topography of corticostriatal projections. Neuroscience 73, 761-781.

Dommett, E., Coizet, V., Blaha, C. D., Martindale, J., Lefebvre, V., Walton, N., Mayhew, J. E., Overton, P. G., and Redgrave, P. (2005). How visual stimuli activate dopaminergic neurons at short latency. Science 307, 1476-1479.

Feger, J., Bevan, M., and Crossman, A. R. (1994). The projections from the parafascicular thalamic nucleus to the subthalamic nucleus and the striatum arise from separate neuronal populations - a comparison with the corticostriatal and corticosubthalamic efferents in a retrograde fluorescent Double-Labelling study. Neuroscience 60, 125-132.

Frank, M. J., and Claus, E. D. (2006). Anatomy of a decision: striatoorbitofrontal interactions in reinforcement learning, decision making, and reversal. Psychol. Rev. 113, 300-326.

Frank, M. J., Scheres, A., and Sherman, S. J. (2007). Understanding decisionmaking deficits in neurological conditions: insights from models of natural action selection. Philos. Trans. R. Soc. B Biol. Sci. 362, 1641-1654.

Gerfen, C. R., and Wilson, C. J. (1996). "The basal ganglia," in Handbook of Chemical Neuroanatomy, Vol. 12, Integrated Systems of the CNS, Part III, eds L. W. Swanson, A. Bjorklund, and T. Hokfelt (Amsterdam: Elsevier), 371-468.

Gillies, A. J., and Willshaw, D. J. (1998). A massively connected subthalamic nucleus leads to the generation of widespread pulses. Proc. Roy. Soc. Lond. B Biol. Sci. 265, 2101-2109.

Grantyn, A. A., and Moschovakis, A. K. (2004). "Structure-function relationships in the superior colliculus of higher mammals," in Superior Colliculus: New Approaches, eds W. C.
Hall and A. Moschovakis (Boca Raton: CRC Press Inc), 107-145.

Graybiel, A. M. (1978). Organisation of the nigrotectal connection: an experimental tracer study in the cat. Brain Res. 143, 339-348.

Groenewegen, H. J., GalisdeGraaf, Y., and Smeets, W. J. A. J. (1999). Integration and segregation of limbic corticostriatal loops at the thalamic level: an experimental tracing study in rats. $J$. Chem. Neuroanat. 16, 167-185.

Gurney, K., Prescott, T. J., and Redgrave, P. (2001a). A computational model of action selection in the basal ganglia. I. A new functional anatomy. Biol. Cybern. 84, 401-410.

Gurney, K., Prescott, T. J., and Redgrave, P. (2001b). A computational model of action selection in the basal ganglia. I. A new functional anatomy. Biol. Cybern. 84, 401-410.

Gurney, K., Prescott, T. J., and Redgrave, P. (2001c). A computational model of action selection in the basal ganglia. II. Analysis and simulation of behaviour. Biol. Cybern. 84, 411-423.

Gurney, K., Prescott, T. J., and Redgrave, P. (2001d). A computational model of action selection in the basal ganglia. II. Analysis and simulation of behaviour. Biol. Cybern. 84, 411-423.

Haber, S. N. (2003). The primate basal ganglia: parallel and integrative networks. J. Chem. Neuroanat. 26, 317-330.

Harting, J. K., Huerta, M. F., Hashikawa, R., Weber, J. T., and Van Lieshout, D. P. (1988). Neuroanatomical studies of the nigrotectal projection in the cat. $J$. Comp. Neurol. 278, 615-631.

Harting, J. K., Updyke, B. V., and VanLieshout, D. P. (2001a). Striatal projections from the cat visual thalamus. Eur. J. Neurosci. 14, 893-896.

Harting, J. K., Updyke, B. V., and VanLieshout, D. P. (2001b). The visual-oculomotor striatum of the cat: functional relationship to the superior colliculus. Exp. Brain Res. 136, 138-142.

Hikosaka, O., Takikawa, Y., and Kawagoe, R. (2000). Role of the basal ganglia in the control of purposive saccadic eye movements. Physiol. Rev. 80, 953-978.

Hikosaka, O., and Wurtz, R. H. (1983). Visual and oculomotor function of monkey substantia nigra pars reticulata. I. Relation of visual and auditory responses to saccades. J. Neurophysiol. 49, 1230-1253.

Horvitz, J. C. (2000). Mesolimbocortical and nigrostriatal dopamine responses to salient non-reward events. Neuroscience 96, 651-656.

Humphries, M. D., Stewart, R. D., and Gurney, K.N. (2006). A physiologically plausible model of action selection and oscillatory activity in the basal ganglia. J. Neurosci. 26, 12921-12942.

Jay, M. F., and Sparks, D. L. (1987). Sensorimotor integration in the primate superior colliculus. I Motor convergence. J. Neurophysiol. 57, 22-34.

Jhou, T. C., Fields, H. L., Baxter, M. G. Saper, C. B., and Holland, P. C. (2009) The Rostromedial Tegmental Nucleus (RMTg), a GABAergic afferent to midbrain dopamine neurons, encodes aversive stimuli and inhibits motor responses. Neuron 61, 786-800.

Joel, D., and Weiner, I. (1994). The organization of the basal gangliathalamocortical circuits: open interconnected rather than closed segregated. Neuroscience 63, 363-379.

Knutson, B., and Cooper, J. C. (2005) Functional magnetic resonance imaging of reward prediction. Curr. Opin. Neurol. 18, 411-417.

Krout, K. E., Loewy, A. D., Westby, G. W. M., and Redgrave, P. (2001). Superior colliculus projections to midline and intralaminar thalamic nuclei of the rat. J. Comp. Neurol. 431, 198-216.

Lin, C. S., May, P. J., and Hall, W. C. (1984) Nonintralaminar thalamostriatal projections in the gray squirrel (Sciurus carolinensis) and tree shrew (Tupaia glis). J. Comp. Neurol. 230, 33-46.

Lindvall,O., andBjorklund,A. (1974)."The organization of catcholamine neurons in the rat central nervous system," in Handbook of Psychopharmacology, Vol 9, eds L. Iversen, S. D. Iversen, and S. H. Snyder (New York: Plenum), 1-48.

May, P. J. (2006). "The mammalian superior colliculus: laminar structure and connections," in Neuroanatomy of the Oculomotor System. Prog. Brain Res. Vol. 151, ed. J. A. Buttner-Ennever (Amsterdam: Elsevier), 321-378.

May, P. J., and Hall, W. C. (1984) Relationships between the nigrotectal pathway and the cells of origin of the predorsal bundle. J. Comp. Neurol. 226, 357-376.

May, P. J., McHaffie, J. G., Stanford, T. R., Jiang, H., Costello, M. G., Coizet, V., Hayes, L. M., Haber, S. N., and Redgrave, P. (2009). Tectonigral projections in the primate: a pathway for pre-attentive sensory input to midbrain dopaminergic neurons. Eur. J. Neurosci. 29, 575-587.

McClure, S. M., Berns, G. S., and Montague, P. R. (2003). Temporal prediction errors in a passive learning task activate human striatum. Neuron 38, 339-346

McHaffie, J. G., Jiang, H., May, P. J., Coizet, V., Overton, P. G., Stein, B. E., and Redgrave, P. (2006). A direct projection from superior colliculus to substantia nigra pars compacta in the cat. Neuroscience 138, 221-234.
McHaffie, J. G., Stanford, T. R., Stein, B. E., Coizet, V., and Redgrave, P. (2005). Subcortical loops through the basal ganglia. Trends Neurosci. 28, 401-407.

Mena-Segovia, J., Bolam, J. P., and Magill, P.J.(2004). Pedunculopontine nucleus and basal ganglia: distant relatives or part of the same family? Trends Neurosci. 27, 585-588.

Mengual, E., de las Heras, S., Erro, E., Lanciego, J. L., and Gimenez-Amaya, J. M. (1999). Thalamic interaction between the input and the output systems of the basal ganglia. J. Chem. Neuroanat. 16, 187-200.

Middleton, F. A., and Strick, P. L. (2000). Basal ganglia and cerebellar loops: motor and cognitive circuits. Brain Res. Rev. 31, 236-250.

Mink, J. W. (1996). The basal ganglia: focused selection and inhibition of competing motor programs. Prog. Neurobiol. 50, 381-425.

Montague, P. R., Dayan, P., and Sejnowski, T. J. (1996). A framework for mesencephalic dopamine systems based on predictive Hebbian learning. J. Neurosci. 16, 1936-1947.

Nambu, A., Tokuno, H., and Takada, M. (2002). Functional significance of the cortico-subthalamo-pallidal "hyperdirect” pathway. Neurosci. Res. 43, 111-117.

O’Doherty, J. P., Dayan, P., Friston, K., Critchley, H., and Dolan, R. J. (2003). Temporal difference models and reward-related learning in the human brain. Neuron 38, 329-337.

Omelchenko, N., and Sesack, S. R. (2005). Laterodorsal tegmental projections to identified cell populations in the rat ventral tegmental area. J. Comp. Neurol. 483, 217-235.

Omelchenko, N., and Sesack, S. R. (2010). Periaqueductal gray afferents synapse onto dopamine and GABA neurons in the rat ventral tegmental area. $J$. Neurosci. Res. 88, 981-991.

Parent, A., and Hazrati, L. N. (1995). Functional anatomy of the basal ganglia.1. the cortico-basal gangliathalamo-cortical loop. Brain Res. Rev. 20,91-127.

Prescott, T. J., Gonzalez, F. M. M., Gurney, K., Humphries, M. D., and Redgrave, P. (2006).A robot model of the basal ganglia: behavior and intrinsic processing. Neural. Netw. 19, 31-61.

Raczkowski, D., and Rosenquist, A. C. (1983). Connections of the multiple visual cortical areas with the lateral posterior-pulvinar complex and adjacent thalamic nuclei in the cat. $J$. Neurosci. 3, 1912-1942.

Redgrave, P., and Gurney, K. (2006). The short-latency dopamine signal: a role in discovering novel actions? Nat. Rev. Neurosci. 7, 967-975. 
Redgrave, P., Gurney, K., and Reynolds, J. (2008). What is reinforced by phasic dopamine signals? Brain Res. Rev. 58, 322-339.

Redgrave, P., Marrow, L. P., and Dean, P. (1992a). Anticonvulsant role of nigrotectal projection in the maximal electroshock model of epilepsy - II. Pathways from substantia nigra pars lateralis and adjacent peripeduncular area to the dorsal midbrain. Neuroscience 46, 391-406.

Redgrave, P., Marrow, L. P., and Dean, P. (1992b). Topographical organization of the nigrotectal projection in rat: evidence for segregated channels. Neuroscience 50, 571-595.

Redgrave, P., Mitchell, I. J., and Dean, P. (1987). Descending projections from the superior colliculus in rat: a study using orthograde transport of wheatgerm-agglutinin conjugated horseradish peroxidase. Exp. Brain Res. 68, 147-167.

Redgrave, P., Prescott, T., and Gurney, K. N. (1999a). The basal ganglia: A vertebrate solution to the selection problem ? Neuroscience 89, 1009-1023.

Redgrave, P., Prescott, T. J., and Gurney, K. (1999b). Is the short latency dopamine response too short to signal reward error? Trends Neurosci. 22, 146-151.

Reiner, A. (2010). “The conservative evolution of the vertebrate basal ganglia," in Handbook of Basal Ganglia Structure and Function, eds H. Steiner and K. Y. Tseng (Burlington, MA: Academic Press), 29-62.

Reynolds, J. N., and Wickens, J. R. (2002). Dopamine-dependent plasticity of corticostriatal synapses. Neural. Netw. $15,507-521$.
Schultz, W. (1998). Predictive reward signal of dopamine neurons. $J$. Neurophysiol. 80, 1-27.

Shen, W.X., Flajolet, M., Greengard,P., and Surmeier, D. J. (2008). Dichotomous dopaminergic control of striatal synaptic plasticity. Science 321, 848-851.

Smith, Y., Bevan, M. D., Shink, E., and Bolam, J. P. (1998). Microcircuitry of the direct and indirect pathways of the basal ganglia. Neuroscience 86, 353-387.

Smith, Y., Raju, D.V., Pare, J. F., and Sidibe, M. (2004). The thalamostriatal system: a highly specific network of the basal ganglia circuitry. Trends Neurosci. 27, 520-527.

Snaith, S., and Holland, O. (1990). "An investigation of two mediation strategies suitable for behavioural control in animals and animats," in From Animals to Animats: Proceedings of the First International Conference on the Simulation of Adaptive Behaviour, eds J.-A. Meyer and S. Wilson (Cambridge, MA: MIT Press), 255-262.

Sparks, D. L. (1986). Translation of sensory signals into commands for control of saccadic eye movements: role of the primate superior colliculus. Physiol. Rev. 66, 118-171.

Stein, B. E., and Meredith, M. A. (1993). The Merging of the Senses. Cambridge, MA: The MIT Press.

Takada, M., Itoh, K., Yasui, Y., Sugimoto, T., and Mizuno, N. (1985). Topographical projections from the posterior thalamic regions to the striatum in the cat, with reference to possible tectothalamo-striatal connections. Exp. Brain Res. 60, 385-396.

Takada, M., Tokuno, H., Ikai, Y., and Mizuno, N. (1994). Direct projections from the entopeduncular nucleus to the lower brainstem in the rat. J. Comp. Neurol. 342, 409-429.

Thorndike, E. L. (1911). Animal Intelligence. New York: Macmillan.

Thorpe, S. J., and Fabre-Thorpe, M (2001). Seeking categories in the brain. Science 291, 260-263.

Tokuno, H., Takada, M., Ikai, Y., and Mizuno, N. (1994). Direct projections from the deep layers of the superior colliculus to the subthalamic nucleus in the rat. Brain Res. 639, 156-160.

Tulloch, I. F., Arbuthnott, G. W., and Wright, A. K. (1978). Topographical organization of the striatonigral pathway revealed by anterograde and retrograde neuroanatomical tracing techniques. J. Anat. 127, 425-441.

Ungless, M. A. (2004). Dopamine: the salient issue. Trends Neurosci. 27, 702-706.

Updyke, B. V. (1981). Projections from visual areas of the middle suprasylvian sulcus onto the lateral posterior complex and adjacent thalamic nuclei in cat. J. Comp. Neurol. 201, 477-506.

Van der Werf, Y. D., Witter, M. P., and Groenewegen, H. J. (2002). The intralaminar and midline nuclei of the thalamus. Anatomical and functional evidence for participation in processes of arousal and awareness. Brain Res. Rev. 39, 107-140.

Voorn, P., Vanderschuren, L. J., Groenewegen, H. J., Robbins, T. W. and Pennartz, C. M. (2004). Putting a spin on the dorsal-ventral divide of the striatum. Trends Neurosci. 27, 468-474.

Wickens, J. (1993). A Theory of the Striatum. Oxford: Pergamon.
Wickens, J. R., Horvitz, J. C., Costa, R. M., and Killcross, S. (2007). Dopaminergic mechanisms in actions and habits. J. Neurosci. 27, 8181-8183.

Winn, P. (2006). How best to consider the structure and function of the pedunculopontine tegmental nucleus: evidence from animal studies. J. Neurol. Sci. 248, 234-250.

Wise, R. A. (2004). Dopamine, learning and motivation. Nat. Rev. Neurosci. 5, 483-494.

Zink, C. F., Pagnoni, G., MartinSkurski, M. E., Chappelow, J. C., and Berns, G. S. (2004). Human striatal responses to monetary reward depend on saliency. Neuron 42, 509-517.

Conflict of Interest Statement: The authors declare that research was conducted in the absence of any commercial or financial relationships that could be construed as potential conflict of interest.

Received: 30 July 2010; paper pending published: 12 August 2010; accepted: 26 August 2010; published online: 22 September 2010. Citation: Redgrave P, Coizet V, Comoli E, McHaffie JG, Leriche M, Vautrelle $N$, Hayes LM and Overton P (2010) Interactions between the midbrain superior colliculus and the basal ganglia. Front. Neuroanat. 4:132 doi: 10.3389/ fnana.2010.00132

Copyright (c) 2010 Redgrave, Coizet, Comoli, McHaffie, Leriche, Vautrelle, Hayes and Overton. This is an open-access article subject to an exclusive license agreement between the authors and the Frontiers Research Foundation, which permits unrestricted use, distribution, and reproduction in any medium, provided the original authors and source are credited. 